\title{
SINGULARIDADES DA MONTAGEM FOTOGRÁFICA EM FABIANA WIELEWICKI
}

Lúcia Helena Fidelis Bahia

\section{RESUMO}

A pesquisa aborda a produção fotográfica de Fabiana Wielewicki (Londrina, 1977). As questões tratadas em seu trabalho foram consideradas a partir dos seguintes aspectos: fotografia-artifício, fotografia-revelação, fotografia-enigma. Esses aspectos permitem à artista construir suas fotografias dialogando com a técnica da montagem e fazendo dela seu artifício principal.

Palavras Chave

Fabiana Wielewicki, fotografia, montagem.

\section{Abstract}

This research approaches Fabiana Wielewicki's photographic production. The topics treated on her work were considered according to the following aspects: photography-artifice, photography-reveal, photography-enigma. Those aspects allow the artist to build her pictures engaging in a dialog with the photomontage technique, and making this technique her main artifice.

Key words

Fabiana Wielewicki, photography, photomontage.

O presente texto aborda o processo de construção imagética da artista paranaense Fabiana Wielewicki ${ }^{1}$ a partir da fotomontagem. Filha de um amante da fotografia, Fabiana buscou, na faculdade de Artes Plásticas, experimentar diversas linguagens como forma de se desvencilhar de uma possível influência paterna na linguagem fotográfica. Assim, durante a graduação e como uma forma de refúgio, ela recorreu a procedimentos como a gravura e a pintura, aperfeiçoando a prática fotográfica apenas ao final do curso. Como a própria artista reconheceu em entrevista à jornalista Néri Pedroso, "foi bem importante a minha decisão, porque

\footnotetext{
${ }^{1}$ FABIANA WIELEWICKI é formada no Mestrado em Artes Visuais (UFRGS, 2005) e Bacharelado em Artes Plásticas (UDESC, 2001). Atualmente cursa Doutorado em Arte e Design na Universidade do Porto, Portugal.
} 
consegui ver o que estava fazendo com a fotografia, que sempre era mais forte para os meus trabalhos"”.

A decisão foi muito significante para Fabiana Wielewicki perceber a importância da fotografia enquanto obra de arte. Em um mundo onde todas as pessoas são capazes de enquadrar um pedaço de história com um click e possuem fácil acesso ao meio que permite esse registro, o que faz de alguém um bom fotógrafo? Em um espaço no qual as imagens se tornaram vulgarizadas por sua produção indiscriminada, como encontrar um olhar singular?

A partir desse questionamento será proposta a análise de algumas obras da Fabiana Wielewicki através dos seguintes instrumentos: fotografia-artifício, apontando questões relacionadas ao método com que ela questiona e observa o fragmento; fotografia-revelação, questionando a maneira com que a artista carrega o olhar do observador através de suas imagens; fotografia-enigma, na qual suas imagens são capazes de guardar segredos na mesma atitude em que os revela, jogando com o enigma-revelação e a realidade-ficção. Esses instrumentos contraídos permitem que a artista construa suas fotografias dialogando com a técnica da montagem e fazendo dela seu principal artifício.

\section{Fotografia-artifício}

Para que a fotografia seja fiel ao seu pensamento, Fabiana Wielewicki utiliza artifícios que tragam a imagem para perto de sua vivência e faz dela uma leitura de seu olhar para o mundo. A fotografia é basicamente isso: um fragmento escolhido entre tantos outros para carregar um desejo. A prática fotográfica se vale da utilização de imagens provocadoras, carregadas de todos os detalhes do mundo sensível em sua realidade-fragmentada, tornando-se o suporte ideal para a faculdade de recordar uma emoção que nos transporte, que nos emocione, que envolva a memória visual. Assim, o fragmento em Fabiana Wielewicki é a singularidade que se reflete em seu processo artístico pois, este, foragido de seu

\footnotetext{
${ }^{2}$ PEDROSO, Néri. Segunda Natureza. Revista eletrônica "Um ponto e outro", vinculada ao Museu Victor Meirelles, referente a exposição $2^{a}$ Natureza de Fabiana Wielewicki ocorrida em 2008/2007.
} 
contexto, torna-se algo em si mesmo, como é possível ser observado na figura abaixo pertencente a série $2^{\underline{a}}$ Natureza:

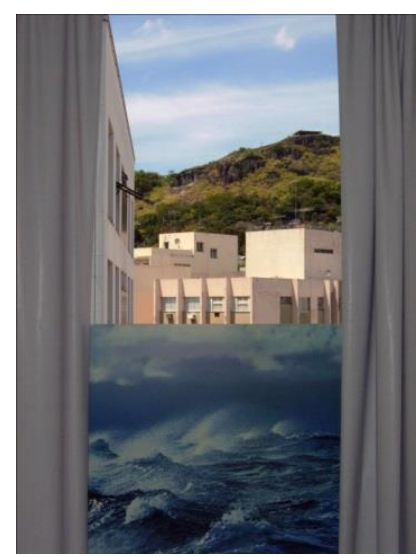

1. Fabiana Wielewicki. Sem título (da série 2aㅡ natureza: $8^{o}$ andar), 2006.

Fotografia: $105 \times 80 \mathrm{~cm}$. Acervo particular.

A figura 1 é carregada de elementos da natureza, sobrepostos em planos, do mesmo modo que ela gostaria de observá-los em seu cotidiano. Em um primeiro momento ela apenas observa. Observa de dentro de seu apartamento através da janela, a qual é representada pela cortina no primeiro plano. Depois, ela imagina. Imagina, como se estivesse de olhos fechados a lembrar, seus abismos inalcançáveis representados pelo mar e pelo céu, localizados em um segundo plano da fotografia, o qual intercala seus limites. Por fim, ela abre os olhos. Olha o que realmente está a sua volta, seu espaço de convívio, observa as construções representadas no terceiro plano, construções ainda rodeadas de resquícios da natureza.

A técnica utilizada pela artista nesta fotografia é a sobreposição de imagens aparentemente aleatórias da natureza. A montagem fotográfica permite ao espectador compartilhar o jogo de re-arranjar fragmentos e é nesse jogo que a artista expõe sua ironia. A fotografia de Fabiana se concretiza como um deslocamento do olhar que permite à paisagem ser lida em suas múltiplas possibilidades. As paisagens construídas pelo olhar da artista são comparáveis a fragmentos que convidam a se desarticular, para que se recomponham através de 
combinações imaginárias sem $\mathrm{fim}^{3}$. Elas são como as fotografias antigas para Susan Sontag: "uma foto é apenas um fragmento e, com a passagem do tempo, suas amarras se afrouxam. Ela se volta à deriva num passado flexível e abstrato, aberto a qualquer tipo de leitura"

\section{Fotografia-revelação}

A revelação é um recurso pouco utilizado na técnica da montagem. Para Fabiana Wielewicki utilizá-la em seu processo, ela recorre ao jogo da imaginação. No cotidiano, o jogo da imaginação encontra-se na fotografia enquanto permanência do registro de uma ausência que encantou o olhar. $O$ olhar da artista faz de suas fotografias uma leitura de um mundo a ser desvendado pelo observador, e reciclado para seu cotidiano.

As imagens do item fotografia-revelação refere-se à ficção e a ilusão, a possibilidade de construção de um cenário que tangencia o mundo real e o mundo ficcional, a fantasia da própria realidade, como pode ser observado nas figuras 2 , 3 e 4. De acordo com Régis Debray, "o mágico é uma propriedade do olhar" ${ }^{5}$. Com seu olhar singular, a artista vai arranjando suas fotografias, criando paisagens dentro da paisagem na qual habita, pois só é possível compreender as coisas sobrenaturais, através do brilho delas sobre as coisas naturais.

Na figura 2, pertencente à série Os Segredos da Boa Fotografia, há uma de espécie de fenda que carrega o olhar do observador para uma perspectiva ao longe, distanciando-o das questões mais próximas do primeiro plano. Esta fotografia ironiza a função tradicional do repoussoir, recurso utilizado nas pinturas barrocas, o qual assegura por um objeto ou uma zona vazia no primeiro plano, o sentimento de uma hierarquia na profundidade. Ao utilizar as construções nas laterais da imagem, Fabiana Wielewicki reforça a perspectiva ao fundo, negando a própria figuração e

\footnotetext{
${ }^{3}$ LIMA, Sérgio. A aventura surrealista. Campinas, SP: Editora da UNICAMP; São Paulo: UNESP; Rio de Janeiro: Vozes, 1995.

${ }^{4}$ SONTAG, Susan. Sobre fotografia. Tradução: Rubens Figueiredo. São Paulo: Companhia das Letras, 2004. Pag. 86.

5 DEBRAY, Régis. Vida e Morte da Imagem: uma história do olhar do Ocidente. Tradução: Guilherme Teixeira. Petrópolis, RJ: Vozes, 1993. Pág. 34.
} 
apresentando a imaginação como plano principal. Isso ocorre como se essas construções fossem cortinas que velassem a figuração e deixassem a vista apenas um pequeno pedaço de um vazio, considerado material de desejo e impulso para imaginação.

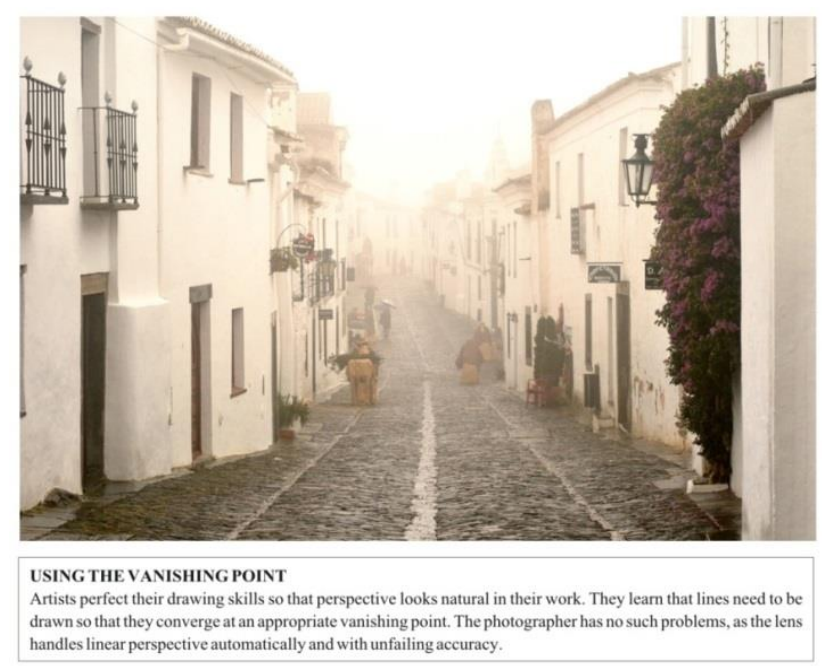

2. Fabiana Wielewicki. The Secrets, 2011. Impressão fotográfica: 70 x $100 \mathrm{~cm}$. Acervo particular.

O vazio da cena da fotografia acima pode ser lido como a própria artista descreveu em relação às fotografias da série Do Outro Lado: "a narrativa não é linear e nunca termina. O outro lado, embora muito desejado, nunca é alcançado. A imagem do mar aparece como abismo, desconhecido, onde a terra acaba e as dúvidas começam"6. O mar, assim como o céu, manifesta-se para Fabiana Wielewicki como uma necessidade que the escapa aos sentidos, mas não a imaginação pois, através de suas fotografias, ela o experimenta vitalmente enquanto necessidade real.

\footnotetext{
${ }^{6}$ Texto produzido por Fabiana Wielewicki e publicado junto com a série "Do Outro Lado".
} 


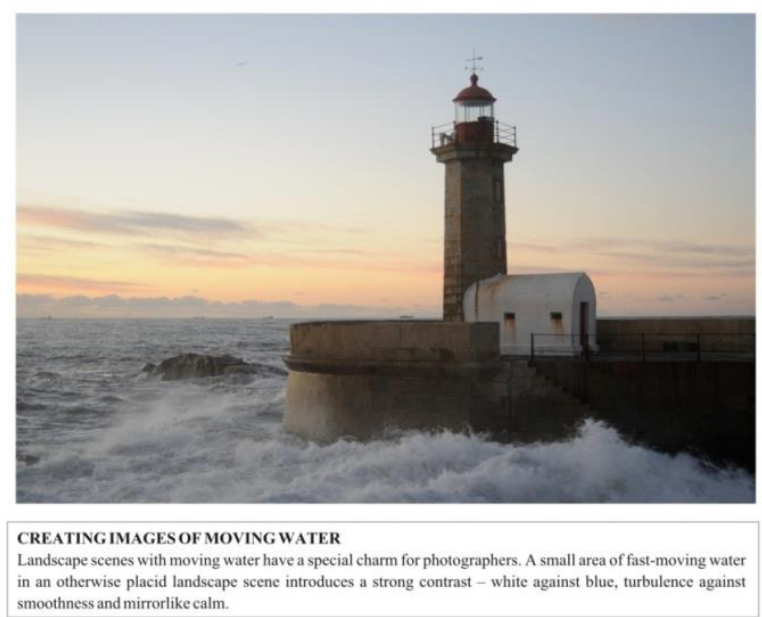

3. Fabiana Wielewicki. The Secrets,2011. Impressão fotográfica: 70 × $100 \mathrm{~cm}$.Acervo particular.

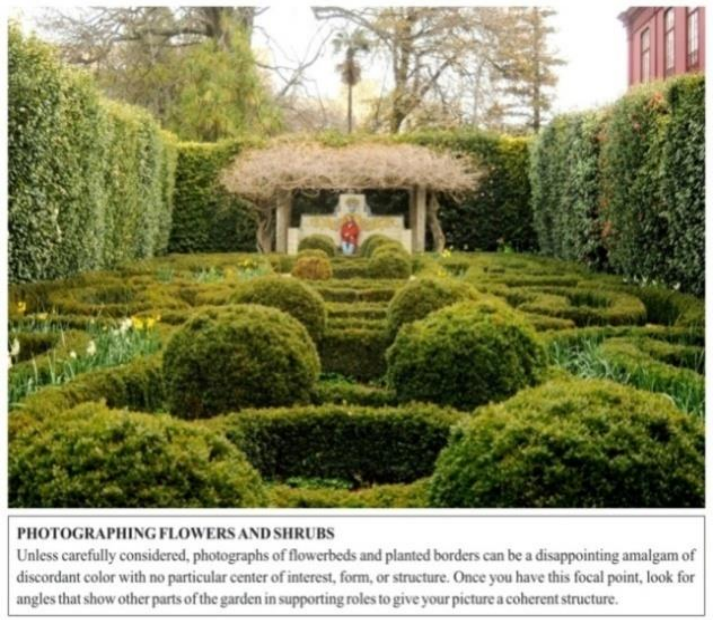

4. Fabiana Wielewicki. The Secrets,2011. Impressão fotográfica: 70 x $100 \mathrm{~cm}$.Acervo particular.

Nas fotografias 3 e 4, Fabiana Wielewicki se liberta da presença das cortinas imaginárias, assim como da figura da janela. Suas formas apresentam-se soltas no enquadramento, demonstrando a liberdade de jogar da fotógrafa. As construções existem, mas estão tomadas quase igualmente por elementos da natureza. Realidade e ficção se unem, permitindo que seus limites se mesclem em uma mesma imagem não delimitada por planos.

Na ficção, a artista permite inventar o que existe do outro lado. Do outro lado da consciência, do outro lado da realidade, do outro lado da janela. De acordo com seus escritos, ao acordar ela espia o dia e fecha a cortina. Fabiana Wielewicki vê seu apartamento como uma ilha e, dentro dele, encontra a possibilidade de reinventar o mundo lá fora. Como ela mesma descreveu: estar conceitualmente cercada de mar tem me intrigado/Certa temporada em outra cidade me fez ver que esta condição faz parte da minha ideia de mim mesma. A fotografia é capaz de afastar as barreiras transparentes que separam o espectador da realidade. Assim, 0 mundo que está "lá fora" passa estar "dentro" das fotografias e, de seu apartamento, a fotógrafa pode desarticulá-lo e remontá-lo infinitamente até encontrar a paisagem que melhor revele sobre seu cotidiano. 


\section{Fotografia-enigma}

Nas imagens que seguem, continuação da série Os Segredos da Boa Fotografia, é perceptível novamente a ironia da Fabiana Wielewicki composta do jogo mostra-esconde que define 0 item fotografia-enigma. Suas fotografias desdobram a perpetuação do tempo, os enigmas que definem, através da imagem, 0 tempo que passa e o tempo que sobra, como pode ser observado nas figuras 5 e 6 . Esse tempo capaz de atravessar o silêncio de um fragmento e se manter intocado e inalcançável ${ }^{7}$.

$\mathrm{Na}$ perpetuação do tempo, a fotografia faz da realidade imagem mental (memória) conservando a aura e a marca do real que lhe deu origem. A imagem fotográfica contém a memória de uma presença/realidade, torna-se evidência ${ }^{8}$. Ela permanece como forma impregnada, simulacro daquilo que desejamos lembrar e é, através dela, que a artista estabelece a figura de seu desejo e demarca a ação de seu imaginário sobre ela. A relação entre o tempo e a memória. De acordo com Aristóteles, "a imagem mental, derivada das impressões sensoriais, compara-se a uma espécie de retrato pintado onde chamaremos de memória o estado de permanência"9.

Como relatou Octavio Paz, "não é a memória que recorda o passado, mas o passado que volta. E o que chamei, em outro contexto, a encarnação das imagens"10. A encarnação das imagens é uma função de nossa memória que permite que as fotografias que nos rodeiam emitam simulacros em si mesmos aos quais o olhar do espectador fragmenta-os e imprime-os em seu cérebro, guardandoos em seu arquivo visual. É por essa razão que, de todos os sentidos, o sentido da visão é o que mais impressiona. Ele produz o espelhamento da imagem de fora como um fragmento e o configura em uma imagem inesquecível. A ação do imaginário sobre as imagens do real.

\footnotetext{
${ }^{7}$ KOSSOY, Boris. Tempo da Fotografia: o efêmero e o perpétuo. Cotia, SP: Atêlie Editorial, 2007.

${ }^{8}$ LIMA, 1995.

${ }^{9}$ LIMA, 1995. Pág. 443.

${ }^{10}$ LIMA, 1995. Pág. 405.
} 

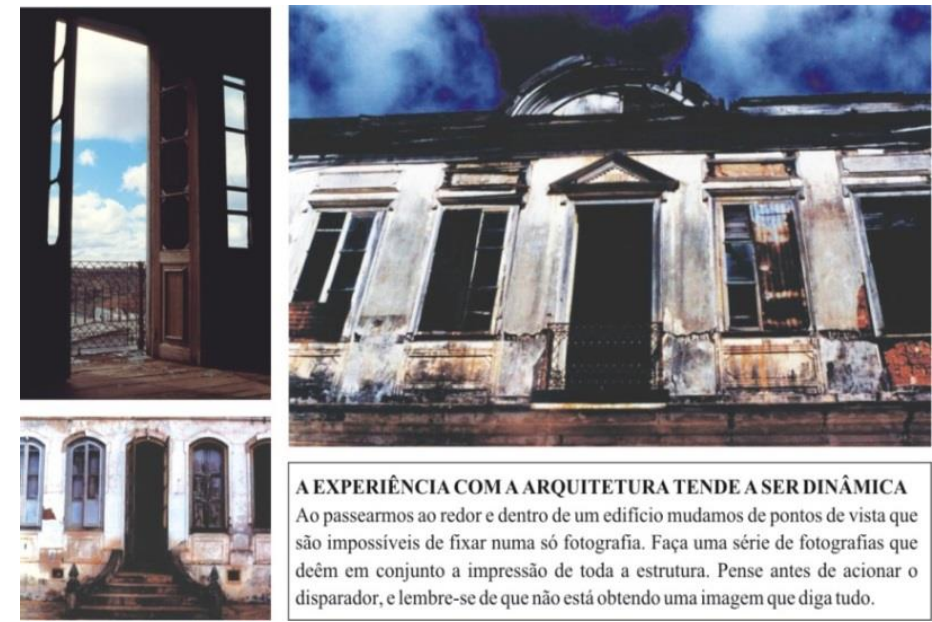

AEXPERIÊNCIA COM A ARQUITETURA TENDE ASER DINÂMICA Ao passearmos ao redor e dentro de um edificio mudamos de pontos de vista que são impossiveis de fixar numa só fotografia. Faça uma série de fotografias que deêm em conjunto a impressão de toda a estrutura. Pense antes de acionar 0 disparador, e lembre-se de que não está obtendo uma imagem que diga tudo.

5. Fabiana Wielewicki. A experiência com a arquitetura tende a ser dinâmica, 2003. Impressão fotográfica: 70 x $60 \mathrm{~cm}$. Acervo particular

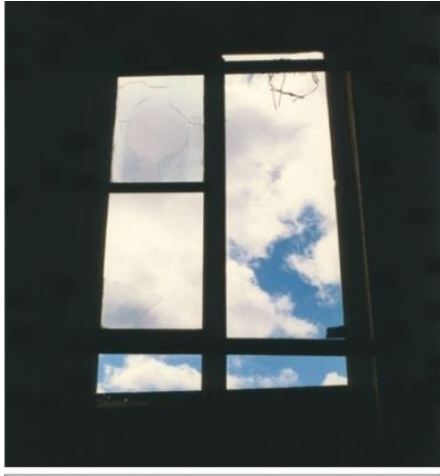

FOTOGRAFE OCÉE

Todos os fotografos sabem que céus espetaculares produzen paisagens espetaculares, mas muito poucos apontam suas máquina
para cima, fazendo do céu o objeto da fotografia. Use os filtros parpara cima, fazendo do céu o objeto da fotografia. Use os filtros parf

6. Fabiana Wielewicki. Fotografe o céu. 2003. Impressão fotográfica: $100 \times 70 \mathrm{~cm}$. Acervo particular.

As imagens 5 e 6 voltam a sobrepor planos e olhares. A janela apresenta-se em primeiro plano dividindo $o$ interior do exterior. $O$ ponto de fuga é sempre 0 exterior, mas apenas o olhar o atinge através da fotografia: o olhar da artista vindo de dentro e o olhar do observador carregado até aquele lugar. O céu parece tão distante e inatingível. As casas abaixo da varanda, que de tão pequenas, parecem de brincadeira. $O$ ângulo superior utilizado nessas fotografias faz um paralelo com a imaginação, com a facilidade de revirar a maneira de olhar habitual, uma forma de atingir o topo da imaginação representando o que há de mais inalcançável. A fotografia é o meio que autoriza a artista saquear de sua própria imaginação uma realidade a via de desaparecer.

\section{Fotografia-montagem}

A fotomontagem é capaz de abranger diversos signos em uma mesma imagem, como é facilmente visualizado nas obras o pintor belga René Magritte (1898-1967) que construiu enigmas em seus quadros-puzzles de jogos intelectuais colocando a realidade em questão e aproximando-se dos conceitos da collage em suas pinturas surrealistas ${ }^{11}$. Assim como Magritte, Fabiana Wielewicki pretende

\footnotetext{
${ }^{11}$ SANTOS, Carolina Junqueira dos. A ordem secreta das coisas: René Magritte e o jogo do visível. Belo Horizonte, 2006.
} 
desconcertar o espectador de sua percepção habitual através do confronto. Referente ao quadro A Condição Humana, de Magritte, Giulio Carlo Argan escreveu: "ambiguidade entre uma imagem da realidade (o quadro) e uma imagem de uma imagem da realidade (o quadro no quadro). A pintura é acuradamente verídica: o trompe l'oeil, a ilusão de ótica, torna-se ilusão psicológica"12.

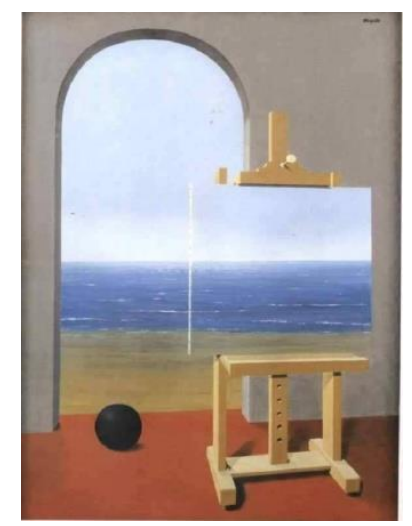

7. René Magritte. A Condição Humana II, 1935. Óleo sobre tela. Bruxelas, coleção Mme.

Referente às paisagens de Fabiana Wielewicki, Aline Dias ${ }^{13}$ relatou "a Fabiana vai mesmo a praia. Com o livro aberto diante do mar. A imagem da paisagem. Ou a paisagem como imagem. Ou a paisagem dentro da imagem. Ou a imagem dentro da paisagem"14. A realidade tenta ser absorvida pela sua representação, transforma o fragmento em matéria dinâmica. Na figura 8, a fotógrafa contrapõe os dois planos utilizados na figura 1. Ela sentada na praia, no exterior ao seu ambiente de convívio, a sua imagem-sonho, a sua imagem-desejo, que percorre sua produção artística quando ela se muda da ilha. Ela sentada na varanda, com o mesmo livro, sonhando a paisagem dentro da paisagem fragmentada de sua realidade cotidiana. Longe do mar, perto da cidade. Isso ocorreu porque a artista concluiu que, quando se mudou para Porto Alegre, viver em uma ilha influenciava seu trabalho.

\footnotetext{
12 ARGAN, Giulio Carlo. Arte Moderna. Tradução: Denise Bottmann e Federico Carotti. São Paulo: Companhia das Letras, 1992. Pág. 480.

${ }^{13}$ Artista e Mestranda em Poéticas Visuais no Programa de Pós-Graduação do Instituto de Artes da Universidade Federal do Rio Grande do Sul.

${ }^{14}$ Sobre o mar, o pôr-do-sol e a solidão, por Aline Dias.
} 

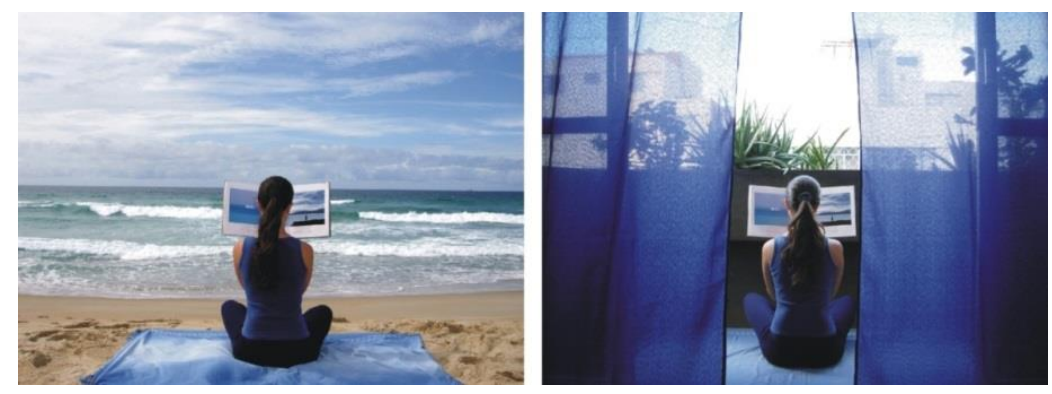

8. Fabiana Wielewicki. Azul marinho: díptico. 2007. Fotografia (digital C print): $50 \times 150 \mathrm{~cm}$. Acervo particular.

Assim, a técnica da montagem dialoga com a maneira de fotografar da artista relacionando a escolha de fragmentos e recortes ao enquadramento, pois uma imagem captada depende do olhar humano e de uma decisão, muitas vezes inconsciente. Fabiana Wielewicki não utiliza apenas a objetiva da câmera para representar a relação com a janela e seu enquadramento, ela permite que a própria figura da janela preencha a paisagem. Com isso, ela consegue em uma mesma imagem não apenas aprisionar o interior e o exterior, mas também o que existe entre eles. A janela torna-se o principal caminho para a imaginação da artista beirar 0 inalcançável. Cada objeto fotografado por ela passa a inventar o seu próprio espaço, o seu próprio tempo e destinar-se a si próprio. A montagem pensada na contemporaneidade como um ato banal torna-se a distinção do trabalho da fotógrafa que entendeu essa técnica utilizando todos os artifícios recorridos pela fotografia. $O$ fragmento, a revelação, o enigma são características que transformam a fotografiamontagem em seu modo de olhar - um fenômeno interior como uma forma de leitura do mundo exterior. 